\title{
AO FEMINISMO DECOLONIAL NA AMÉRICA LATINA ${ }^{1}$
}

\author{
Hacia el Feminismo Decolonial en América Latina
}

\author{
Ana Marcela MONTANARO MENA \\ Universidad Carlos III \\ anamarcelamontanaro@gmail.com \\ Tradução de Heloisa WOSNIAK \\ Universidade Federal do Paraná \\ helloheloisaw@gmail.com \\ https://orcid.org/0000-0001-7219-1764
}

\begin{abstract}
RESUMO: O feminismo hegemônico ocidental e eurocentrista não conseguiu reconhecer que sua prática reproduzia os mesmos problemas que criticava. Enquanto colocava em dúvida o universalismo androcêntrico, produziu categorias que foram aplicadas com uma pretensão de universalidade. A meados dos anos 70 do século XX começa-se a questionar essa pretensão a partir de um feminismo elaborado pelos feminismos pós-coloniais que apontam a denunciar o caráter eurocêntrico do feminismo hegemônico e da forma em que este reproduz a colonialidade. O feminismo decolonial na América Latina pretende subverter os conceitos do feminismo hegemônico incorporando as vozes de mulheres subalternas, constituindo a decolonização do feminismo uma proposta teórica e de compromisso ético que aponta a construção de novas formas de relação política e acadêmica a partir da heterogeneidade.
\end{abstract} PALAVRAS-CHAVE: América Latina; Decolonial; Feminismo; Terceiro Mundo.

RESUMEN: El feminismo hegemónico occidental y eurocentrista no logró reconocer que su práctica reproducía los mismos problemas que criticaba. Mientras ponía en duda el universalismo androcéntrico, produjo categorías que fueron aplicadas con una pretensión de universalidad. A mediados de los años 70 del siglo XX se empieza a poner en cuestionamiento esa pretensión desde un feminismo elaborado por los feminismos poscoloniales que apuntan a denunciar el carácter eurocéntrico del feminismo hegemónico y de la forma en que este reproduce la colonialidad. El feminismo decolonial en América Latina pretende subvertir los conceptos del feminismo hegemónico incorporando las voces de mujeres subalternas, constituyendo la decolonización del feminismo una

\footnotetext{
${ }^{1}$ Publicação original: MONTANARO MENA, A. M. Hacia el Feminismo Decolonial en América Latina. Investigación joven con perspectiva de género, v.1, ed. 1, 2016, p. 336-355.
} 
propuesta teórica y de compromiso ético que apunta a la construcción de nuevas formas de relación política y académica desde la heterogeneidad. PALABRAS-CLAVE: América Latina; Decolonial; Feminismo; Tercer Mundo.

\section{INTRODUÇÃO}

O feminismo hegemônico ocidental e eurocentrista, produzido por mulheres brancas, urbanas, burguesas e de Primeiro Mundo, não conseguiu reconhecer que sua prática reproduzia os mesmos problemas que criticava. Enquanto colocava em dúvida o universalismo androcêntrico, produziu categorias de gênero e as aplicou com uma pretensão de universalidade.

A meados dos anos 70 começa a colocar-se em questionamento essa pretensão a partir de um feminismo elaborado pelas "mulheres de cor e do Terceiro Mundo", que será nutrido pelos aportes das feministas pós-coloniais, construindo através do tempo um conjunto de contribuições dispersas geograficamente, mas situadas geopoliticamente no Terceiro Mundo ou na periferia do conhecimento e que apontam a denunciar o caráter eurocêntrico, etnocêntrico e universalizador do sujeito do feminismo hegemônico e da forma em que este reproduz a colonialidade.

$\mathrm{Na}$ América Latina, decolonizar o feminismo é uma proposta não só teórica, mas também de compromisso político para desconstruir o conhecimento eurocêntrico e apontar as carências do sujeito assumido desde uma pretensão universal. Além disso, aponta a construção de novas formas de relação política a partir da heterogeneidade, assim como novas práticas, diferentes e alternativas às impostas pelo patriarcado capitalista.

Este trabalho é o resultado de uma investigação bibliográfica que tem por objetivo principal descrever a relação existente entre essas teorias e as teorias e críticas feministas que se desenvolvem a partir do Terceiro Mundo global, prestando atenção às propostas do feminismo decolonial latino-americano em contraposição ao feminismo hegemônico ocidental e eurocêntrico que sugere a construção de um Terceiro Feminismo.

O presente estudo é fruto de um compromisso acadêmico, ético e político situado. Sou uma mulher latino-americana, que há muito tempo, e provavelmente, sem saber teoricamente a princípio, questionei o feminismo que olha e determina quem é ou não é "feminista", que indica quais são as "opressões que sofremos e padecemos" e que vê as mulheres que viemos do Terceiro Mundo, não só a partir da alteridade, mas também a partir de um olhar diferente e que nos assume desde uma retórica salvacionista, um feminismo ocidental que segue atualmente reproduzindo a colonialidade. 
As investigações acadêmicas realizadas a partir do compromisso com o lugar que ocupamos no mundo brindam a possibilidade de estudar e aprofundar temas que nos comprometam mais além do teórico.

\section{HIPÓTESE}

Esta investigação parte da hipótese de que os estudos da modernidade/colonialidade e os feminismos pós-coloniais negros, de cor, de Terceiro Mundo e feminismos de mulheres do sudeste asiático têm sido referentes na construção do feminismo decolonial na América Latina.

\section{METODOLOGIA}

O presente estudo é resultado de uma rigorosa investigação bibliográfica, que se desenvolve no marco acadêmico do programa Mestrado Universitário em Estudos Avançados em Direitos Humanos, da Universidade Carlos III de Madri.

\section{RESULTADOS}

\section{Os outros olhares feministas}

No final da década dos anos setenta e pela preponderância e visibilidade dos movimentos sociais, começa-se a traçar nos Estados Unidos e na Europa, a ideia de construir um movimento feminista internacional para lutar de maneira conjunta contra o patriarcado. Entretanto, esse objetivo começa a ser questionado por algumas mulheres índias, negras, chicanas, indígenas e lésbicas, que iniciam uma série de críticas que apontaram a visibilizar que o sujeito construído pelo feminismo hegemônico branco, ocidental, se define a partir da diferença sexual da mulher em relação ao homem e não visibiliza outras diferenças que são constitutivas da subjetividade, sejam a raça, a etnia, a sexualidade e a classe social (PORTOLÉS, 2004).

É no cenário descrito onde se constitui o eixo articulador dos questionamentos do feminismo, de onde emergirão, no meio desse debate, os antecedentes de uma genealogia feminista de caráter crítico e contra hegemônico (MELONI, 2012, p. 143).

Essas vozes orientaram suas críticas a colocar em suspeita, entre outros temas, o sujeito universal de mulher e as questões sobre o gênero e a dicotomia masculinofeminino. Explicitando seu mal-estar em relação à teoria e prática feminista hegemônica 
europeia e norte-americana, revelam as limitações do feminismo ocidental hegemônico e eurocêntrico que se baseia exclusivamente nos valores da Modernidade e da Ilustração.

O feminismo hegemônico ocidental, por suas raízes teóricas e históricas, conduz que em sua análise e construção faça-se referência a um único sujeito-objeto de conhecimento conceitualizado em termos universalizantes, não estabelecendo relação com a história, com binários homem/mulher e entendendo que o patriarcado é supostamente a única opressão comum a todas as mulheres, isto é, uma concepção de identidade feminina determinada, que se presumia igual a todas as mulheres e, portanto, a necessidade de uma luta comum.

Durante os feminismos do século $\mathrm{XX}$, a conexão entre gênero, classe $\mathrm{e}$ heterossexualidade, como assuntos racializados, não havia sido explicitada (LUGONES, 2005, p. 62). A episteme feminista clássica, produzida por mulheres brancas, urbanas, burguesas, de classe média e que viviam em países ocidentais do Primeiro Mundo, não reconhecia:

Que sua prática reproduzia os mesmos problemas que criticava. Enquanto colocava em dúvida o universalismo androcêntrico, produziu a categoria de gênero e a aplicou universalmente a toda a sociedade e a toda cultura, sem sequer poder dar conta da maneira em que o sistema de gênero é um constructo que surge para explicar a opressão das mulheres nas sociedades modernas ocidentais e, por tanto, seria substantivo (ESPINOSA, 2014b, p. 7).

Essas teóricas iniciam o desenvolvimento de diferentes conceitos de feminismos situados a partir do Terceiro Mundo, nos quais se incluem termos como negro, antirracista, de fronteira, feminismos periféricos, descolonial, decolonial, não ocidentais ou da terceira onda (BIDASECA, 2010), agrupados neste trabalho na categoria de feminismos pós-coloniais.

Essas denominações são usadas nas investigações e teorias feministas para fazer referência à denúncia que iniciaram as novas correntes feministas a respeito dos feminismos hegemônicos ocidentais, etnocentristas e eurocentristas. O feminismo póscolonial "[...] reedita um feminismo do "Terceiro Mundo" [...] que englobaria tanto às mulheres oprimidas pela raça no "Primeiro Mundo" quanto às mulheres de países descolonizados" (BIDASECA, 2011, p. 98-99).

Deve advertir-se que em certas ocasiões o termo feminismo pós-colonial tem sido usado, sobretudo, para referir-se à produção teórica das feministas do sudeste asiático e as africanas (árabes e subsaarianas), mas esse conceito também serve para nomear às 
feministas chicanas, mulheres de cor, negras e do Terceiro Mundo que têm criticado o colonialismo discursivo do feminismo branco, sobretudo pela repercussão dos seus estudos pós-coloniais (HERNÁNDEZ, 2011 [2008], p. 81).

O surgimento dos chamados feminismos com uma tradição pós-colonial tem sido medular para fazer uma crítica aos "mapas homogeneizadores do feminismo clássico" (SIERRA, 2013, p. 217). Essas teorias feministas rompem com a ideia de que o patriarcado é a única opressão sofrida por "todas as mulheres", pelo que realizam planejamentos sugestivos, fazendo uma intersecção entre gênero, sexo, raça, nacionalidade, subalternidade e classe social. Partem da premissa de que o gênero é racializado e que a raça sempre generaliza. Desse modo, pode-se compreender melhor a subalternização e suas diversas variáveis, mas além da categoria sexo-gênero. Ao mesmo tempo, dão a ver as formas de resistência, para evidenciar os espaços de dominação nos lugares de transformação e resistência individual e coletiva.

Neste trabalho se assume a proposta dos feminismos pós-coloniais como aqueles que constituem um conjunto de contribuições feministas dispersas geograficamente, mas situadas geopoliticamente no Terceiro Mundo ou na periferia do conhecimento e que apontam a denunciar o caráter eurocêntrico, etnocêntrico e universalizador do sujeito do feminismo hegemônico e da forma em que este reproduz a colonialidade. A seguir se desenvolverão considerações sobre a relação desses feminismos com a proposta de decolonizar o pensamento e a práxis feminista.

\section{As novas epistemologias e metodologias feministas. Colonização no discurso e práxis feminista.}

O pensamento feminista clássico e hegemônico foi desenvolvido por um grupo concreto de mulheres, que por suas origens de classe, etnia, raça e nacionalidade ou bem situação geográfica possui e disfruta de uma vantagem epistêmica. Dessa maneira, o cruzamento entre a epistemologia pós-colonial e a epistemologia feminista pretende visualizar a existência de "uma inquietante proximidade entre os discursos coloniais e os de algumas representantes do feminismo ocidental, que se expressam em termos salvacionistas pelo caminho do modelo ocidental" (BIDASECA, 2010, p. 21) e a partir do privilégio de enunciação de feministas, não só a partir do Norte, mas também daquelas que a partir do Sul reproduzem tais discursos, olhares teóricos e práxis.

É por isso que as contribuições dos feminismos pós-coloniais incorporam novas metodologias de investigação, a partir de novos paradigmas. Isso implica não somente situar-se ética e politicamente a partir de um local geográfico ou a partir de uma Revista X, v. 16, n. 1, p. 239-258, 2021. 
posição de poder acadêmico (HARAWAY, 1995), mas também de que a investigação da práxis feminista deve partir de com quem trabalhamos ou a partir dos sujeitos sobre os quais investigamos, como portadores de conhecimento e de capacidades agenciais (MAHMOOD, 2011 [2001]).

Essas críticas trazem consigo a busca de novas respostas e, com isso, de novas propostas feministas, que procuram reconhecer as diferenças históricas, culturais e geográficas e a partir delas surgem diferentes propostas teóricas feministas, que têm por objetivo dar visibilidade à importância do reconhecimento das diferenças culturais e históricas para o avanço de novas práxis de luta e tomada de posição ética e política feminista, que sejam inclusivas e respeitosas da pluralidade de experiências das diversas identidades de gênero.

A partir dos aportes feministas pós-coloniais se incluem novos olhares, mais além das dicotomias e hierarquizações do masculino e feminino no contexto do sistema patriarcal, assumido pelo feminismo hegemônico ocidental como o fundamento da opressão e discriminação, ao incorporar categorias de subalternidade e interseccionalidade, que permitem novas reflexões e conceitualizações relacionadas com a classe social, a raça, a etnia e a sexualidade.

A partir dessas contribuições, passa-se a relacionar o colonialismo, o imperialismo e o nacionalismo, tornando complexas as opressões resultantes que são fundamentos do capitalismo globalizado que, por sua vez, é hétero-patriarcal e racista. Porque "o colonialismo não é um período histórico superado, um fóssil inerme” (SUÁREZ, 2011 [2008], p. 31), continua sendo uma semente que cresce e se reproduz visivelmente em novas formas de colonialidade.

\section{América Latina: A decolonização do feminismo: A ruptura com o feminismo hegemônico.}

Na América Latina, Mendoza (2014a [2009]), Curiel (2007) e Espinosa (2009) apontam que o feminismo também tem, assim como nos Estados Unidos e na Europa, uma base burguesa, classe média, urbana, acadêmica, branca e heteronormativa, que em sua maioria provém da esquerda. Esse é um dado que tem especial relevância, pois as feministas da América Latina se nutriram das contribuições do feminismo europeu e norte-americano, que continua sendo a tese de subalternidade de Spivak (2003 [1988]) e o colonialismo discursivo apontado por Mohanty (2011a [1986]). Com o eurocentrismo e o colonialismo presentes na produção teórica e na práxis política do feminismo 
hegemônico, é lógico que o feminismo latino-americano tenha sido herdeiro da carga etnocentrista que lhe é própria.

Depois dos processos de democratização na América Latina, vividos na década dos anos 80 e 90, as feministas latino-americanas, com o objetivo de participar nos processos democráticos que se iniciavam, se agruparam nos postulados do "feminismo anglo-saxão (tanto o liberal, radical, como o marxista) para construir suas organizações e planejamentos alternativos à mudança social e cultural" (MENDOZA, 2014a, p. 250). Sobretudo porque os projetos de democratização, que coincidem com o fim da Guerra Fria, seguem de mãos dadas com o avanço das políticas neoliberais impostas pelos centros de poder à América Latina.

Mendoza (2014a, p. 254) questionou como o neocolonialismo opera a partir da implantação da ideologia da democracia nas realidades pós-coloniais latino-americanas a partir de uma "lógica imperial/colonial", que se esclarece a partir da cooperação e da ajuda ao desenvolvimento das conferências das Nações Unidas de Direitos Humanos, que tem reconfigurado as relações entre o centro hegemônico e a periferia, e o interior de cada Estado, a partir do discurso da democracia neoliberal das estratégias do Consenso de Washington, Fundo Monetário Internacional, Agência dos Estados Unidos para o Desenvolvimento Internacional (AID) e o Banco Interamericano de Desenvolvimento que pintam de democracia suas políticas antissociais.

Mendonza (2014a, p. 254) considera que na América Latina aconteceu uma colonialidade da democracia, já que "em nenhum momento se reestabelece o poder popular ou ocorre uma emancipação da lógica da dominação militar a nível interno nem a dominação imperial externa, mas apenas reveste-se de uma nova linguagem e institucionalidade" que não rompe com as estruturas da colonialidade. A democracia liberal na América Latina, a partir da década dos anos 80, continuou sendo compatível com os projetos de colonização do poder imperial e com os sistemas locais de dominação interna, que dependem e reproduzem seus ditados.

Nessa dinâmica, o feminismo articula suas lutas, fazendo-se, inclusive, cúmplice do avanço do neoliberalismo e do projeto neocolonial, fortalecendo com isso a estrutura socioeconômica, político-cultural excludente, mecanismos que fortalecem o poder do patriarcado, a violência, a corrupção dos aparatos militares e das antigas ditaduras.

De ser coletivos autônomos e com uma agenda política própria, começaram a transformar-se em organizações não governamentais (ONGs), para suprir "ao estado de estruturas organizativas e vínculos com as mulheres dos setores populares para implementar suas políticas sociais neoliberais" (MENDOZA, 2014a, p. 253). 
Assim, passaram a depender do financiamento de organismos internacionais e de agendas políticas transnacionais.

Ao mesmo tempo, muitas mulheres que vinham do movimento feminista, e outras que se vincularam, irromperam o cenário político à raiz da crescente institucionalização estatal visível nos ministérios e institutos da Mulher, pelas cotas de participação política e pelas políticas públicas com perspectiva de gênero, apoderando-se de um discurso e uma práxis de "gênero", esvaziado do compromisso ético-político com as demandas daquelas mulheres sobre as que recaem as políticas neoliberais.

Na América Latina, a colonialidade das práticas discursivas dos feminismos hegemônicos se evidencia não somente na reprodução de estratégias para conformar outras práticas do feminismo latino-americano, sejam as das mulheres dos povos indígenas, das afrodescendentes, das trabalhadoras, das lésbicas, das camponesas, das prostitutas, das mulheres pobres, mas também a aparição de "uma colonialidade intrínseca aos discursos produzidos pelos feminismos latino-americanos" (ESPINOSA, 2009, p. 45), que se visualiza na dependência com os feminismos hegemônicos ocidentais, que determinam os delineamentos políticos do feminismo local e, com isso, a absorção de mulheres subalternas que foram silenciadas pelas mulheres não somente representantes das oligarquias internas e das feministas hegemônicas latino-americanas.

Concordando com a feminista boliviana Julieta Paredes, assume-se que com o auge das políticas neoliberais, impostas na América Latina desde inícios dos anos oitenta, e sendo na década dos noventa onde começa a ser mais forte a chamada equidade de gênero, dotada de sua estratégia, o empoderamento das mulheres foi parte do discurso da chamada governabilidade:

Que [...] tem como objeto aplacar qualquer âmago de insubordinação às políticas econômicas, nesse caso, às políticas neoliberais, com a ameaça de: ou você se incluiu ou será excluído e excluída dos circuitos de circulação do capital, da informação, do desenvolvimento, do emprego e da modernidade capitalista (PAREDES, 2012, p. 92).

Em meio a esse contexto, um grupo de feministas autônomas iniciou o desenvolvimento de um pensamento teórico e uma práxis política que pretendiam que as intersecções de desigualdade de raça, etnia, classe, sexo e gênero, em que vivem uma grande porcentagem das mulheres latino-americanas, fossem visibilizadas, e emergem vozes que além de reivindicar e problematizar ditas condições de raça, também apontam a desafiar a lógica etnocêntrica, racista, misógina, heterossexual e colonial que estão 
presentes nos feminismos ocidentais e daquelas feministas que na América Latina reproduzem a colonialidade.

As primeiras vozes questionadoras sobre a forma em que uma boa parte das feministas latino-americanas se inseriam nesses processos se visibilizaram no VI Encontro Feminista Latino-americano e do Caribe em El Salvador em 1993 e, no VII Encontro, realizado em Cartagena de Chile em 1996, unem-se às mulheres do feminismo autônomo outras mais jovens e, desse enfrentamento intrafeminista, surge, em 1996, a Declaração do Feminismo Autônomo, que "aglutinou os esforços e a perspectiva contra-hegemônica de toda uma corrente de feministas radicais durante a década de noventa" (ESPINOSA; GÓMEZ; OCHOA, 2014a, p. 25).

A partir da crítica, tanto teórica quanto de práxis política do feminismo hegemônico, a necessidade de se criar um feminismo autônomo que se distanciasse do feminismo institucional, insurge como um feminismo que é reapropriado pelas mulheres que foram construídas como as outras, marcando uma resistência ao feminismo ocidental, que a partir do centro penetra nas periferias do mundo não branco, e que a partir das políticas públicas e vozes com privilégios de enunciação reproduz os discursos e a práxis da colonialidade. É um feminismo que se tece a partir da resistência, para romper o espaço desde onde foram construídas as relações de poder e assim tecer, com seu próprio fio, sua própria história.

O feminismo autônomo latino-americano foi questionando mais além de questionar que a autonomia é um marco político, que transcende a dicotomia institucionalidade versus autonomia, reforça a urgência de que:

[...] articular e transpassar essa perspectiva de modo de pensar como se expressam as relações de poder, de raça, de classe, de sexualidade, em contextos pós-coloniais; pois, ainda que o colonialismo não seja o mesmo desde a chegada dos conquistadores europeus, a colonialidade foi marcada em nosso contexto, em nossos corpos, em nossas vidas, inclusive em muitos dos projetos feministas, e isso se concretiza na dependência ideológica, política, material que ainda boa parte do feminismo mantém nas suas teorias e discursos, em suas práticas e na vida pessoal de muitas (ESPINOSA et al., 2014a, p. 25-26).

As feministas autônomas vincularam-se também aos processos e movimentos sociais que questionavam o projeto das democracias neoliberais, isso às acercou a "novas formas de compreensão da matriz de opressão que explicaria a subordinação das mulheres e as comunidades de origem subalterna" (ESPINOSA, 2012a, p. 116) e a assumir novos olhares feministas a partir dos estudos pós-coloniais, da colonialidade 
do poder, da violência epistêmica, evidenciando como o racismo e o capitalismo são inerentes ao gênero.

O feminismo latino-americano, que se separa do institucional e se reivindica a partir da autonomia teórica e política, pretende desenvolver uma proposta que permita:

[...] articular a condição das mulheres e outros indivíduos subalternos como tipos de sujeitos produzidos dentro do regime de gênero e (hétero) sexualidade, com a condição de (pós) colonialidade e dependência em que são produzidos tais indivíduos. Trata-se da configuração de um espaço de preocupação, denúncia e produção de saber que indaga e permite encontrar as interconexões entre o copo político de gênero e o corpo produzido por determinadas condições geopolíticas, históricas e epistêmicas: um corpo gerado, (hétero) sexualizado, mas também racializado, oprimido e explorado pelo capital e pelas políticas neocoloniais (ESPINOSA, 2012b, p. 8).

Confrontam a aposta legislativa e as políticas públicas a favor das mulheres as evidenciando como:

[...] novas práticas de domínio patriarcal que, impulsionadas ao compasso dos organismos financeiros internacionais e dos organismos de cooperação de países ricos, sustentam-se sobre o modelo hegemônico do capital e dos discursos que os mantêm, homogeneizando as demandas e necessidades das mulheres. A partir dessa homogeneidade é impossível construir práticas diferentes e alternativas às impostas pelo patriarcado capitalista e transformá-lo (GARGALLO, 2012, p. 71-72).

Reconhece-se que se bem a legislação e as políticas públicas em prol da emancipação legal e do direito de viver sem violência controlam a realidade misógina, isso não é suficiente, porque no dia de hoje, a discriminação e a violência se manifestam na esfera da violação à legalidade. Por isso é urgente, a partir de vozes heterogêneas e ações autônomas, que a partir do feminismo sejam potencializadas relações e diálogos mais do que convenções e conferências. Como sinaliza Gargallo (2012, p. 72):

[...] para abrir-se a desvendar paradigmas dominantes do que é a libertação para as mulheres, considerando os lugares a partir de onde as mulheres de Nossa América [...] enfrentam as formas de opressão, dominação e centralização que terminam por, uma vez atrás de outra, criminalizar sua denúncia da injustiça e seu protesto. 


\section{A proposta decolonial do feminismo na América Latina}

O grupo do movimento feminista se afastou do feminismo hegemônico e traçou um percurso epistêmico aproximando-se da tradição do pensamento latino-americanista que desde os anos setenta tenta apostar na produção de um conhecimento do outro, situado geopoliticamente (CASTELLI; ESPINOSA, 2011, p. 193). Sousa (2008, p. 52) o denominou epistemologias do Sul, referindo-se a novos conhecimentos, geopoliticamente inspirados na América Latina e no Sul global, que se contrapõem às epistemologias dominantes do Norte global. O que tem sido denominado feminismo decolonial se insere nesses novos conhecimentos e é "um movimento em pleno crescimento e amadurecimento que se proclama revisionista da teoria e da proposta política do feminismo a partir do que se considera seu viés ocidental, branco e burguês” (ESPINOSA et al., 2014a, p. 32).

Com a emergência de "outro horizonte de sentido histórico" (QUIJANO, 2009) o giro decolonial (MIGNOLO, 2007, p. 26-27) ou, tão somente, a decolonialidade, que se volta a construir um novo modo de produção do conhecimento, uma forma distinta de pensamento e desenvolvimento de um paradigma do "outro" em respeito à modernidade e à ordem de dominação global iniciado com a conquista e colonização da América, afirma que este se mantém na atualidade, mas "apontando à possibilidade de falar sobre $<<$ mundos e conhecimentos de outro modo $>>$ que sejam também possíveis" (ESCOBAR, 2003, p. 53).

$\mathrm{Na}$ América Latina, a proposta decolonial feminista apresenta complexidades que articulam posições críticas e contra-hegemônicas que vão desde o pós-colonialismo e a colonialidade e se concentram em elaborar e adscrever um novo programa feminista, dentro de uma perspectiva situada histórica e geopoliticamente a partir da colonialidade do poder, assumida como processo, que começou com a chegada dos europeus aos territórios que hoje são a América e trouxe consigo a imposição e a dominação estrutural de uma cultura sobre a outra, processo que permeia as práticas econômicas, sociais e políticas mediante a interiorização de valores, práticas e normas alheias a quem é colonizado. A colonialidade como padrão de poder se inicia segundo Quijano (2009, p. 342):

[...] com a constituição da América (Latina), no mesmo momento e no mesmo movimento histórico, o emergente poder capitalista se torna mundial, seus centros hegemônicos se localizam nas zonas situadas sobre o Atlântico - que depois se identificarão como Europa - e como eixos centrais de seu novo padrão de dominação se estabelecem também a colonialidade e a modernidade. Logo, com a América (Latina) o capitalismo se torna mundial, euro centrado e a colonialidade e a 
modernidade se instalam associadas com os eixos constitutivos de seu padrão de poder específico até os dias de hoje.

Foi María Lugones quem nomeou pela primeira vez, em 2007, um projeto de feminismo decolonial, propondo articular tanto a perspectiva da interseccionalidade desenvolvida pelo feminismo negro e de cor nos Estados Unidos quanto a leitura crítica da modernidade desenvolvida por Quijano (2009 [2007]).

O feminismo decolonial é um conceito que se elabora no marco dos estados neoliberais e de sociedades profundamente desiguais e racistas: [...] pretende dar conta da condição concreta das mulheres não brancas através das urgências que lhes são próprias, tendo em conta a imbricação das relações de classe, de raça e de gênero (BOUTELDJA, 2014, p. 80). O movimento põe ao descoberto "a tensão entre a superação do colonialismo e a persistência da colonialidade, que regula tanto as identidades de sexo/gênero quanto as raciais e políticas" (BIDASECA; OBARRIO; DE OTO; SIERRA, 2013, p. 5). Ele dirige sua crítica contra o racismo estrutural, o sexismo e o imperialismo que estão presentes nas instituições, nos discursos e na política, visibiliza e evidencia a:

Resistência ao feminismo experimentado ao mesmo tempo no Ocidente entre as populações não brancas e no Terceiro Mundo e a realidade massiva e inquietante das violências multidimensionais exercidas sobre mulheres não brancas, violências produzidas pelos Estados e o neoliberalismo (BOUTELDJA, 2014, p. 79).

Decolonizar o feminismo implica assumir uma posição teórica, ética e política que passe pelo pensamento, pela ação individual e coletiva e que elabore um conjunto teórico que parta das vivências próprias das mulheres no contexto latino-americano, com o objetivo de construir um pensamento próprio.

Esta proposta deseja assumir a compreensão da história de opressão histórica que marcou o colonialismo e o neocolonialismo na América Latina e como esta opressão se reproduz por meio das:

[...] políticas neoliberais que coloca ao chamado Terceiro Mundo em uma situação global desigual frente aos países do Norte, mas, além disso, significa entender que no interior de nossos contextos existem relações de poder estruturais, cotidianas que continuam afetando a mulheres racializadas, etnizadas, a lésbicas, às mais pobres, porque apesar do que se fala da era pós, elas continuam sendo os principais escudos do patriarcado, por não corresponder ao paradigma da modernidade (CURIEL, citada por ESPINOSA et al., 2014a, p. 26).

Ofeminismodecolonial recuperaolegado das mulheres feministas afrodescendentes e indígenas (RIVERA, 2011) que desde a América Latina apresentam o problema da 
invisibilidade dentro de suas próprias comunidades, dos movimentos sociais, políticos e do próprio feminismo.

As feministas afrodescendentes latino-americanas e do Caribe evidenciam as sequelas da colonialidade que se escondem por trás do discurso da mestiçagem que tem sido em grande medida o causador da violência racista e classista. Elas têm mostrado as maneiras como conseguiram unir esforços a partir da solidariedade e as diversas formas para resistir à escravidão (CURIEL, 2007).

Desde o feminismo indígena, questionam-se as relações patriarcais racistas, classistas e sexistas presentes nas sociedades da América Latina. Igualmente, permitem visualizar e revelam como dentro de suas próprias comunidades se entremesclam as diversas opressões disfarçadas de costumes e tradições. Desde aí surge uma proposta de feminismo comunitário que some esforços na decolonização do feminismo (GARGALLO, 2012).

As mulheres indígenas, segundo palavras de Cabnal (2010, p. 24), feminista comunitária indígena da etnia maya-xinka, aportam olhares que se fiam a partir de elementos da cosmogonia indígena, promovendo "[...] a libertação da opressão histórica contra os corpos sexuados de mulheres e contra a opressão histórica capitalista da natureza, mas também evocam e invocam as resistências e transgressões ancestrais das mulheres [...]”.

A partir da diversidade do conhecimento, as feministas que pretendem decolonizar o feminismo, assumem a crítica certeira e profunda sobre as pretensões políticas, epistêmicas e discursivas dos feminismos hegemônicos ocidentais e desvendam como eles reproduzem um discurso colonial, colocando ao descoberto como em grande medida as categorias teóricas são reprodutoras do racismo e da lógica colonial.

Discurso que construiu as mulheres do Terceiro Mundo, ou do Sul global, como as outras que precisam ser salvas, o que traz consigo deslocamentos políticos e epistêmicos à racionalidade ocidental do pensamento feminista que se apropriou da história dos feminismos e, com isto, das definições das opressões e das políticas feministas, anulando a história, as lutas e as palavras das outras.

O feminismo decolonial também permite revisar as conexões entre modernidade, capitalismo, patriarcado, racismo e democracia liberal, tornando complexa a mestiçagem como figura retórica sobre a qual se assentam os estados-nação latino-americanos e mediante a qual se nega e exclui do presente da nação as populações indígenas e afrodescendentes. Isso começou com a revisão da ideia de um patriarcado histórico, visualizando e tornando visíveis as capacidades de agência e resistência das mulheres dos povos originários de AbyaYala, antes ainda da existência do feminismo (ESPINOSA et al., 2014a, p. 34). 
Dessa maneira, e se opondo à pretensão acadêmica e discursiva de retórica salvacionista (BIDASECA, 2010) do outro:

[...] a aposta de um feminismo decolonial, ao passo que se nutre de análises críticas anteriores que põem em dúvida as explicações desenvolvidas e sustentadas pela teoria ocidental branco-burguesa, avança e questiona a unidade do conceito "mulher" de uma maneira radicalmente inédita, tanto assim que já é impossível reconstitui-la novamente. Além disso - e este é o ponto de ruptura desde o qual já não é possível voltar atrás - o feminismo, em sua cumplicidade com a aposta decolonial, faz sua a tarefa de reinterpretação da história na crítica à modernidade, já não somente pelo seu androcentrismo e misoginia - como o fez a epistemologia feminista clássica -, mas a partir do seu caráter intrinsecamente racista e eurocêntrico (ESPINOSA et al., 2014a, p. 31).

Decolonizar o feminismo é abrir um novo e fértil campo que aponta a diversidade dos olhares, a reconceituar as opressões, e supõe desafios teóricos e políticos não somente para o feminismo, mas também para as teorias da pós-colonialidade e da colonialidade. Além disso, traz consigo desafios relacionados não somente com o gênero e o patriarcado, mas também com o poder, o Estado, a economia e os Direitos Humanos, pois esse enfoque constitui uma crítica profunda ao capitalismo e à colonialidade ante ao qual milhares de mulheres resistem.

Tal feminismo aponta a necessidade de que se escute às vozes baixas (GUHA, 2002 [1993]), se outorgue voz às subalternas e trate de se reverter a violência epistêmica (epistemicidio) (SPIVAK, 2003, p. 317), a que foram submetidos e despojados os povos originários da América Latina.

Na América Latina, o feminismo decolonial constrói e levou à construção de "uma narrativa sobre as culturas ancestrais indígenas como culturas com um desenvolvimento inédito e diametralmente oposto ao do ocidental" (MENDOZA, 2014b, p. 60). Nesse sentido, a decolonização da epistemologia feminista pretende subverter aos conceitos teóricos do feminismo ocidental e, sobretudo, colocar em suspeita a questão da existência do gênero e do patriarcado nas sociedades ameríndias antes da intrusão europeia.

Lugones (2008; 2011 [2010], p. 106) afirma a inexistência do gênero no mundo pré-colonial. Outras estudiosas questionam o conceito de gênero ocidental, corrente representada pelas pensadoras feministas vinculadas à luta das mulheres indígenas e ao processo revolucionário de Chiapas (GUTIÉRREZ; PALOMO, 1999; HERNÁNDEZ, 2003). Igualmente, Segato (2011, p. 32), entre outras, busca demonstrar que antes da 
colonização espanhola nas sociedades indígenas já existiam nomenclaturas de gênero e se apoia no que Paredes (2014) denominou como cruzamento patriarcal.

Espinosa (2014b, p. 9) ressalta que:

O gênero nunca opera de forma separada e, ainda mais, se estamos atentas a propostas como a de María Lugones a respeito de que essa categoria gênero não explicaria de forma adequada a maneira em que foram submetidas "as mulheres" dos povos não europeus; deveríamos estar dispostas a aceitar o inadequado de um uso universalista da categoria de gênero (a divisão dicotômica do mundo em "mulheres" e "homens") ou ao menos deter-nos sempre (e não em determinadas ocasiões) ao seu uso de uma forma instável e interdependente de outras categorias como raça, classe e localização geopolítica.

\section{Fazendo caminho e tecendo saberes}

Para decolonizar o feminismo, é urgente escutar e recuperar a memória das lutas das mulheres indígenas. Incorporar ao debate feminista suas vozes que criam e recriam, que questionam e criticam as relações ancestrais em suas comunidades, desde uma práxis e teorias que a partir de novas epistemologias, e inclusive cosmogonias, apontem, tal e como diz Cabnal (2010, p. 12), “[...] a reinterpretar as realidades da vida histórica cotidiana das mulheres indígenas, dentro do mundo indígena".

A empresa colonial se assentou na "imposição da forma de pensar e produzir conhecimento em detrimento das múltiplas formas de conhecer, com consequências profundas como a colonialidade do saber" (ESPINOSA et al., 2014a, p. 18).

Assim é urgente que a luta política e as contribuições teóricas e acadêmicas também reconheçam o embate epistêmico contra o saber eurocentrado. Ao incorporar à análise da matriz de opressão e subordinação os conceitos de subalternidade, colonialidade do poder e violência epistêmica, é possível visualizar a forma em que o sistema moderno colonial de gênero é correlativo ao regime heterossexual, ao racismo e ao capitalismo no marco de processos históricos da conquista e da colonização da América Latina (ESPINOSA, 2012a, p. 117).

É necessária uma proposta que facilite a construção de um eixo teórico, pensado para exercer uma prática política que assuma a relação indissolúvel e entre o sexismo, o racismo, a colonialidade, o capitalismo e o patriarcado e que permita "a superação da colonialidade de gênero e esta colonialidade do ser que desumaniza e converte as 
mulheres da colônia em presa não somente dos homens colonizadores, mas também dos homens colonizados" (MENDOZA, 2014b, p. 54).

Assim, é possível que seja necessário voltar o olhar e "reconfigurar os mapas da práxis feminista" para poder olhar de maneira horizontal, a partir dos diálogos Sul-Sul, entendendo que no Norte existe um Sul, que “[...] desenvolve uma crítica profunda ao capitalismo global, à naturalização dos valores do capital e ao poder não reconhecido do relativismo cultural no feminismo acadêmico e suas pedagogias" (SIERRA, 2013, p. 217).

\section{CONCLUSÕES}

Os feminismos hegemônicos que no Norte global, ou daqueles situados no Norte do Sul, não conseguiram romper sua cumplicidade com a colonialidade do poder, pois os olhares da alteridade, o silenciamento das excluídas, das empobrecidas, das mulheres de cor continuam presentes ao assumir a interseccionalidade de maneira isolada sem questionar o padrão da colonialidade do poder, do ser e do saber.

O feminismo situado no Sul geopolítico leva necessariamente a interpelar e questionar as propostas epistemológicas e metodológicas que desde o Norte global geopolítico questionam e desvelam as representações discursivas dos sujeitos construídos a partir da alteridade.

A decolonização do feminismo implica a decolonização da epistemologia feminista. Pretende subverter os conceitos teóricos do feminismo ocidental e por em entredito a questão da existência do gênero e do patriarcado nas sociedades ameríndias antes da intrusão europeia.

Para avançar em uma prática de decolonização é mais importante reconhecer como o conceito de gênero ocidental, na intrusão europeia em territórios ameríndios, serviu para desumanizar tanto as mulheres quanto os homens do mundo colonizado.

A partir do olhar teórico dos feminismos decoloniais, a opressão se assume dentro de um sistema de conhecimento e como um sistema de classificação social dentro do qual surgiram as categorias dominantes de opressão, seja o gênero, a raça e/ou classe social, onde operam de maneira conjunta e nunca de maneira individual.

Na América Latina, decolonizar o feminismo é uma proposta não somente teórica, mas também de compromisso político para desconstruir o conhecimento etnocêntrico eurocêntrico e apontar as carências do sujeito assumido a partir de uma compreensão universal, mas, além disso, aponta a construção de novas formas de relação política a partir da heterogeneidade, assim como novas práticas, diferentes e alternativas às impostas pelo patriarcado capitalista. 


\section{REFERÊNCIAS}

BIDASECA, K. Perturbando el texto colonial. Los Estudios (Pos) coloniales en América Latina. Buenos Aires: Editorial SB, 2010.

BIDASECA, K.; VAZQUEZ LABA, V. "Feminismo e indigenismo. Puente, lengua y memoria en las voces de las mujeres indígenas del sur". In: BIDASECA, K.; VAZQUEZ LABA, V. (Comps.). Feminismos y poscolonialidad. Descolonizando el feminismo desde y en América Latina. Buenos Aires: Ediciones Godot, 2011. p. 361-378.

BIDASECA, K. "Mujeres blancas buscando salvar a las mujeres de color café de los hombres de color café. O reflexiones sobre desigualdad y colonialismo jurídico desde el feminismo poscolonial". In: BIDASECA, Karina e VAZQUEZ LABA, Vanesa (comp.), Feminismos y poscolonialidad. Descolonizando el feminismo desde y en América Latina. Buenos Aires: Ediciones Godot, 2011, p. 95-118.

BIDASECA, K; OBARRIO, J; OTO, A; SIERRA, M. "Introducción”. In: BIDASECA, Karina; OTO, Alejandro de; OBARRIO, Juan; e SIERRA, Marta (Comps.), Legados, Genealogías y Memorias Poscoloniales en América Latina: Escrituras fronterizas desde el Sur. Buenos Aires: Ediciones Godot, 2013, p. 5-15.

BOUTELDJA, H. ¿Feministas o no? Pensar la posibilidad de un «feminismo decolonial» com James Baldwin e Audre Lorde. Tabula Rasa, (v. 21), 2014, p. 77-89.

CABNAL, L. “Acercamiento a la construcción de la propuesta de pensamiento epistémico de las mujeres indígenas feministas comunitarias de AbyaYala". In: Feminismos diversos: el feminismo comunitario. Las Segovias: Acsur, 2010, p. 11-25.

CASTELLI, R; ESPINOSA MIÑOSO, Y. “Colonialidad y dependencia en los estudios de género y sexualidad en América Latina: el caso de Argentina, Brasil, Uruguay y Chile". In: BIDASECA, Karina e VAZQUEZ LABA, Vanesa (Comp.), Feminismos y poscolonialidad. Descolonizando el feminismo desde y en América Latina. Buenos Aires: Ediciones Godot, 2011, p. 191-212.

CURIEL, O. "La crítica postcolonial desde las prácticas políticas del feminismo antirracista". In: Revista Nómadas, Teoría decoloniales en América Latina, (26), 2007, p. $92-101$.

ESCOBAR, A. "Mundos y conocimientos de otro modo. El programa de investigación de modernidad/colonialidad latinoamericano". In: Tabula Rasa, (1), 2003, p. 51-86.

ESPINOSA MIÑOSO, Y. "Etnocentrismo y colonialidad en los feminismos Latinoamericanos: complicidades y consolidación de las hegemonías feministas en el Revista X, v. 16, n. 1, p. 239-258, 2021. 
espacio transnacional". In: Revista venezolana de estudios de la mujer. Vol. 14, (33), 2009 , p. 37-54.

ESPINOSA MIÑOSO, Y. "La política sexual radical autónoma, sus debates internos y su crítica a la ideología de la diversidad sexual". In: MONTES, Patricia (ed.alt), Pensando los feminismos en Bolivia, La Paz: Conexión Fondo de Emancipaciones, Serie Foros 2, 2012 a, p. 113-126.

ESPINOSA MIÑOSO, Y. “Los desafíos de las prácticas teóricopolíticas del feminismo latinoamericano en el contexto actual”. In: DAZA, Mar; HOETMER, Raphael e VARGAS, Virginia (eds.), Crisis y movimientos sociales en nuestra América. Cuerpos, territorios e imaginarios en disputa, Lima: Programa Democracia y Transformación Global -PDTG. Recuperado de: https://www.academia.edu/1097630/Los_desafios_de_las_practicas_ teorico-politicas_del_feminismo_latinoamericano_en_el_contexto_actual, 2012b

ESPINOSA MIÑOSO, Y; GÓMEZ CORREAL, D; OCHOA MUÑOZ, K. "Introducción”. In: ESPINOSA MIÑOSO, Yuderkys; GÓMEZ CORREAL, Diana e OCHOA MUÑOZ, Karina (Eds.), Tejiendo de otro modo: Feminismo, epistemología y apuestas descoloniales en AbyaYala. Popayán: Editorial Universidad del Cauca, 2014a, p. 13-40.

ESPINOSA MIÑOSO, Y. "Una crítica descolonial a la epistemología feminista crítica". In: El Cotidiano, (184), 2014b, p. 7-12.

GARGALLO, F. “La urgencia de retomar nuestra radicalidad”. In: MONTES, Patricia (ed. alt.), Pensando los feminismos en Bolivia. La Paz: Conexión Fondo de Emancipaciones, Serie Foros 2, 2012, p. 69-87.

GUHA, R. Las voces de la historia y otros estudios subalternos. Barcelona: Editorial Crítica, 2002 [1993].

GUTIÉRREZ, M; PALOMO, N. “Autonomía con mirada de mujer”. In: BURGUETE CAL Y MAYOR, Aracelly (Coord.), México: Experiencias de Autonomía Indígena. Guatemala y Copenhague: IWGIA, Grupo Internacional de Trabajo sobre Asuntos Indígenas, Guatemala y Copenhague, 1999.

HARAWAY, D. “Conocimientos situados: la cuestión científica en el feminismo y el privilegio de la perspectiva parcial". In: Ciencia, ciborgs y mujeres. La reinvención de la naturaleza. Valencia: Ediciones Cátedra, 1995, p. 313-344.

HERNÁNDEZ CASTILLO, R. "Re-pensar el multiculturalismo desde el género. Las luchas por el reconocimiento cultural y los feminismos de la diversidad". In: La Ventana. Revista de estudios de género, (18), 2003, p. 9-39. 
HERNÁNDEZ CASTILLO, R. "Feminismos poscoloniales: Reflexiones desde el Sur del Río Bravo". In: SUÁREZ NAVAZ, Liliana e HERNÁNDEZ, Rosalva Aída (Eds.), Descolonizando el feminismo. Teorías y prácticas desde los márgenes. Valencia: Ediciones Cátedra, 2011 [2008], p. 75-113.

LUGONES, M. "Multiculturalismo radical y feminismos de mujeres de color". In: Revista Internacional de Filosofía política, (25), 2005, p. 61-76.

LUGONES, M. “Colonialidad y Género”. In: Tabula Rasa, (9), 2008[2007], p. 73-101.

LUGONES, M. "Hacia un feminismo descolonial”. In: La manzana de la discordia, (6), 2, 2011[2010], p. 105-119.

MAHMOOD, S. "Teoría feminista, agencia y sujeto de liberación: algunas reflexiones sobre el renacimiento islámico en Egipto”. In: SUÁREZ NAVAZ, Liliana e HERNÁNDEZ CASTILlO, Rosalva Aída (Eds.), Descolonizando el feminismo. Teorías y prácticas desde los márgenes. Valencia: Ediciones Cátedra, 2011[2001], p. 165-221.

MELONI, C. Las fronteras del feminismo. Teorías nómadas, mestizas y posmodernas. Madrid: Editorial Fundamentos, 2012.

MENDOZA, B. "Los feminismos y la otra transición a la democracia en América Latina". In: Ensayos de crítica feminista en Nuestra América. México: Editorial Herder, 2014a [2009], p. 235-260.

MENDOZA, B. "La cuestión de la colonialidad de género". In: Ensayos de crítica feminista en Nuestra América. México: Editorial Herder, 2014b [2012], p. 45-71.

MIGNOLO, W. "El pensamiento decolonial: desprendimiento y apertura. Un manifiesto". In: CASTRO GÓMEZ, Santiago e GROSFOGUEL, Ramón, (Comps.), El giro decolonial. Reflexiones para una diversidad epistémica más allá del capitalismo global. Bogotá: Siglo del Hombre Editores, Universidad Central, Instituto de Estudios Sociales Contemporáneos y Pontificia Universidad Javeriana, Instituto Pensar, 2007, p. 25-46.

MOHANTY, C. "Bajo los ojos de Occidente. Academia feminista y discurso colonial". In: HERNÁNDEZ CASTILlO, Rosalva Aída e NAVAZ SUÁREZ, Liliana (Eds.), Descolonizar el Feminismo: Teorías y Prácticas desde los Márgenes. Valencia: Ediciones Cátedra, 2011a [1986], p. 117-163.

PAREDES CARVAJAL, J. "Las trampas del patriarcado". In: MONTES, Patricia (ed. alt.), Pensando los feminismos en Bolivia. La Paz: Conexión Fondo de Emancipaciones, Serie Foros 2, 2012, p. 89-111. 
PAREDES CARVAJAL, J. (2014[2010]). Hilando Fino. Desde el feminismo comunitario, Comunidad mujeres creando comunidad. México: Cooperativa El Rebozo, 2014 [2010].

PORTOLÉS, A O. "Feminismo postcolonial: la crítica al eurocentrismo del feminismo occidental". In: Cuaderno de Trabajo $N^{o}$ 6, Instituto de Investigaciones Feministas de la UCM. Recuperado de: https://www.academia.edu/438330/Feminismo_Postcolonial_La_ Cr\%C3\%ADtica_Al_Eurocentrismo_Del_Feminismo_Occidental, 2004

QUIJANO, A. "Colonialidad del Poder y Clasificación Social”. In: Journal of WorldSystems Research, VI, (2), 2004, p. 242-386.

QUIJANO, A. "Otro horizonte de sentido histórico". In: América Latina en movimiento, 2009. Recuperado de http://www.alainet.org/es/active/37936 consultado por última vez el 1 de abril de 2016, p. 441.

RIVERA ZEA, T. "Mujeres indígenas americanas luchando por sus derechos". In: Suárez Navaz, Liliana y Hernández, Rosalva Aída (Eds.), Descolonizando el feminismo. Teorías y prácticas desde los márgenes. Valencia: Ediciones Cátedra, 2011[2008], p. 331-349.

SEGATO, R. "Género y colonialidad: en busca de claves de lectura y de un vocabulario estratégico descolonial”. In: Bidaseca, Karina y Vazquez Laba, Vanesa (Comps.), Feminismos y poscolonialidad. Descolonizando el feminismo desde y en América Latina. Buenos Aires: Ediciones Godot, 2011, p. 17-47.

SIERRA, M. “Tercer Espacio: Las geografías paradójicas del feminismo y la colonialidad”. In: Bidaseca, Karina; Oto, Alejandro de; Obarrio, Juan; e Sierra, Marta (Comps.), Legados, Genealogías y Memorias Poscoloniales en América Latina: Escrituras fronterizas desde el Sur. Buenos Aires: Ediciones Godot, 2013, p. 211-228.

SPIVAK, G C. ¿Puede hablar elsubalterno?. Revista Colombiana de Antropología, 39, 2003[1988], p. 297-364.

SOUSA SANTOS, B. "El Foro Social Mundial y la izquierda global”. In: El Viejo Topo, (240), 2008, p. 39-62.

SUÁREZ NAVAZ, L. “Colonialismo, Gobernabilidad y Feminismos Poscoloniales”. In: Suárez Navaz, Liliana y Hernández, Rosalva Aída (Eds.), Descolonizando el feminismo. Teorías y prácticas desde los márgenes. Valencia: Ediciones Cátedra, 2011[2008], p. 331349. 